\title{
Support from Teaching Staff and Self-efficacy as Determinants of Students' Perceived Employability: a Longitudinal study
}

\author{
Gerardo Petruzziello $^{1}$, Marco Giovanni Mariani ${ }^{1}$, Dina Guglielmi ${ }^{2}$, Rita Chiesa ${ }^{1}$
}

${ }^{1}$ Department of Psychology, Alma Mater Studiorum-University of Bologna, ${ }^{2}$ Department of Education Studies, Alma Mater Studiorum-University of Bologna.

\begin{abstract}
Perceived employability acquires, for university students, growing importance to deal with occupational uncertainty. This study examines how teaching in university influences perceived employability in a sample of Italian final-year university students. We draw on Conservation on Resources Theory and Career self-management model to hypothesise a positive impact of support from teaching staff on students' perceived employability. We also contend that students' self-efficacy mediates the relationship between support from teaching staff and perceived employability. One hundred fifty-one university students completed a survey three times over 10 months. The results confirm that support from teaching staff enhances students' perceived employability directly and indirectly by shaping students' self-efficacy. Our findings confirm the role of university teachers and their didactical practice to equip their students with career resources.
\end{abstract}

Keywords: Perceived employability; support from teaching staff; self-efficacy; university students; graduate employability. 


\section{Introduction}

In times of increasing labour market volatility, higher education students and graduates see their occupational perspectives challenged. They pay the highest cost of structural employment problems and negative contingencies, like the COVID-19 related economic crisis. More than ever before, Higher Education institutions' role is crucial in helping students have a smooth transition to the labour market by providing them with precious resources.

Accordingly, in this study, we explore perceived employability (hereafter, PE), a prominent resource for managing career transitions, including transitioning to the labour market. We draw upon the Conservation of Resources Theory (COR theory, Hobfoll et al., 2018) and Career Self-Management model (CSM model, Lent \& Brown, 2013) to investigate how supportive teaching in University influence students' perception of being employable. In line with the COR tenets, we posit that support from teaching staff exerts a positive effect on students' PE by adopting teaching behaviours that help students find ways to apply knowledge in practice and deal with the reality of work. We adopt the CSM model to investigate the mediating role of self-efficacy in the relationship between support from teaching staff and students' PE. We apply a longitudinal design to explore the hypothesised relationships with a sample of Italian final-year university students.

Our study expands the knowledge about PE of Higher Education students, which is still in its infancy (Romgens et al., 2020). The focus on support from teaching staff stresses Higher Education's role as a contextual facilitator of students' PE. The inclusion of self-efficacy is a possible explanation of the mechanism through which support from teaching staff exerts its effects. Moreover, our study's relies on longitudinal design, which lacks in the literature about $\mathrm{PE}$ and is functional to produce more robust conclusions.

At a practical level, our results stress the need to shift the role of university teacher from knowledge dispenser to learning manager, who nurture students' confidence with supportive and employability-oriented teaching styles.

What follows is an introduction of study variables, along with the making up of the hypothesised relationships. Then, we deal with the methodology employed and present the results obtained. Eventually, we draw from the results to discuss the theoretical and practical implications, limitations, and research recommendations.

\section{Students' Perceived Employability}

PE - namely, the self-perceived ability and opportunity to attain employment appropriate to one's qualification level (Rothwell et al., 2009; Vanhercke et al., 2014) - results from the psychological approach to employability, which assumes that people act depending on what they perceive rather than objective reality (Vanhercke et al., 2014). People may possess skills 
or have objective environmental facilitations that make them employable. Still, they can adjust appropriately to the current employment environment as long as they appraise their skills as equipment to navigate the labour market (Monteiro et al., 2020). Herein, we understand PE as a personal resource within the COR theory framework, in line with the assumption made by Vanhercke et al. (2014). The central COR theory's tenet is that individuals strive to gain and retain psychological, social, and material resources to deal with stressful conditions, maintain motivation and optimal functioning (Hobfoll et al., 2018). Coherently, PE assists individuals in their career endeavours, promotes the perception of control and confidence (Fugate et al., 2004), facilitates job-seeking processes (Yizhong et al., 2017), and career success (Gonzalez et al., 2015).

Scholarly research has mainly focused on personal determinants of students' PE, such as human and psychological capital (i.e., Donald et al., 2019). The study of contextual PE determinants is still in progress, as it is limited to the labour market's perceptions (i.e., Jackson \& Tomlinson, 2020). We focus on more proximal contextual factors, such as support-oriented university teaching methods embedded in the daily didactical routine.

\section{Support from Teaching Staff and PE}

According to COR theory, factors located at the organisational and environmental level can facilitate resource creation (Hobfoll et al., 2018). We contend that support from teaching staff-namely the 'student's perception of the supervisor's performance in imparting knowledge to students and generally helping them' (Álvarez-González et al., 2017, p. 286) is one of these factors that, within a university learning environment, can foster students' PE. University teachers can exploit their teaching methods to support students in understanding and applying knowledge and positively appraise their learning in terms of impact in real workplaces (Römgens et al., 2020). Teachers may exercise this function through supportive behaviours like involving students in discussions and activities (i.e. work-based exercises and examples, group work) to reflect upon what they learn and how to self-regulate to deal with work-related issues (Liu et al., 2020). Moreover, knowledgeable teachers may provide students with information about available career opportunities (Donald et al., 2018). This research claims that these behaviours shape the students' perception of being employable as they sustain their approach to the world of work. Nevertheless, only a few shreds of evidence confirm a positive relationship between support from teaching staff and PE, with crosssectional data (i.e., Alvarez-Gonzalez et al. 2017). We, therefore, posit that:

Hypothesis 1. Support from teaching staff predicts PE of university students positively. 


\section{The Mediating Role of Self-Efficacy}

CSM model posits that self-efficacy - the experience-based self-cognition on the personal capability to perform a task - drives motivation, persistence, and performance in many career stages, including university-to-work transition (Lent \& Brown, 2013). The CSM model also understands self-efficacy beliefs as a product of learning experiences that convey positive information about the individuals' capability. Support from teaching staff may foster students' self-efficacy by providing them with means (i.e. encouragement, work-based activities and examples) functional to raise confidence in their capabilities and knowledge (Liu et al., 2020). In this way, their self-efficacy grows. Self-efficacy is a primary predictor of PE (Dacre Pool \& Sewell, 2007). People who have faith in their ability to use their learning to face real workplace issues can, in turn, appraise more positively their likelihood to secure employment (Onyishi et al., 2015). Apart from a recent exception focusing on the perception of employability skills (see Liu et al., 2020), no study has investigated the mediating effect of self-efficacy in the supportive teaching-PE relationship. We formulate the following:

Hypothesis 2. Students' self-efficacy mediates the relationship between Support from teaching staff and PE of university students.

\section{Method}

\subsection{Sample}

We collected longitudinal data with final-year students from different Italian Universities, who completed an online questionnaire three times between November 2019 and September 2020. We reached students through agreements with teachers of their degree course. They were given a link to the online questionnaire, granted confidentiality, and given the possibility to provide their informed consent. They could provide their e-mail address separately to be contacted anonymously after the first collection. At the end of the data collection, 151 students completed the questionnaire three times, with a mean age of 25 years, mostly females $(85.6 \%)$.

\subsection{Measures}

We measured the study variables three times. We measured support from teaching staff with 19 items adapted from Elvira et al. (2017), PE with five items developed by Bertson et al. (2006), and self-efficacy with three items developed by Gonzalez-Romà et al. (2016). All scales had a 5-point Likert response scale. We evaluated the internal consistency of the scales. 


\subsection{Data Analysis}

We used support from teaching staff measured at T1, self-efficacy at T2 and PE at T3 to test the hypotheses. We followed the analytical approach developed by Hayes (2018) and used the macro PROCESS on SPSS version 25 to test the hypotheses. The indirect effect was estimated with a 95 per cent confidence interval. Age and gender at Time 3 were introduced to the analysis as control variables.

\section{Results}

Table 1 reports mean values, standard deviations, internal consistency values, and correlations among the study variables. All scales provided good internal consistency values (using Cronbach's alpha). Concerning the hypotheses test (Table 2), the results supported the positive effect of Support from teaching staff on $\mathrm{PE}(\beta=.27 ; \mathrm{p}<.001$; Hypothesis 1$)$, corroborating the crucial role of teaching methods in shaping graduates' upcoming approach to the world of work. The results supported the mediation effect hypothesis $(\beta=.05 ; \mathrm{p}<.05$; Hypothesis 2) and confirmed the mechanism explaining the effect of support from teaching staff on students' PE.

Table 1. Descriptive statistics, internal consistency values and correlation matrix of variables.

\begin{tabular}{|c|c|c|c|c|c|c|c|c|}
\hline Variable & M & SD & Crobach's $\alpha$ & 1 & 2 & 3 & 4 & 5 \\
\hline 1. Gender ${ }^{\mathrm{a}}(\mathrm{T} 3)$ & - & - & - & - & & & & \\
\hline 2. Age (T3) & 25.90 & 5.81 & - & -.14 & - & & & \\
\hline 3. STS (T1) & 3.14 & .69 & .92 & -.12 & .09 & - & & \\
\hline 4. SE (T2) & 3.71 & .58 & .80 & $-.21 *$ & .16 & $.29 * *$ & - & \\
\hline 5. PE (T3) & 3.15 & .69 & .76 & $-.17 *$ & .15 & $.35^{* *}$ & $.30 * *$ & - \\
\hline
\end{tabular}

Table 2. path coefficients for the hypothesised model.

\begin{tabular}{|c|c|c|c|c|c|c|}
\hline \multirow[t]{3}{*}{ Variable } & \multirow{2}{*}{\multicolumn{2}{|c|}{$\frac{\text { SE }}{\text { Direct effect }}$}} & \multicolumn{4}{|c|}{$\mathbf{P E}$} \\
\hline & & & \multicolumn{2}{|c|}{ Direct effect } & \multicolumn{2}{|c|}{ Indirect effect } \\
\hline & $\mathrm{B}$ & SE & B & SE & B & $95 \% \mathrm{CI}$ \\
\hline Age (T3) & .01 & .01 & .01 & .01 & & $\begin{array}{l}\text { [LLCI; } \\
\text { ULCI] }\end{array}$ \\
\hline Gender (T3) & $-.27 *$ & .13 & -.17 & .16 & & \\
\hline STS (T1) & $.21 * * *$ & .07 & $.28 * * *$ & .08 & & \\
\hline $\mathrm{SE}(\mathrm{T} 2)$ & - & - & $.25^{* *}$ & .09 & & \\
\hline $\begin{array}{l}\text { STS }(\mathrm{T} 1) \rightarrow \text { SE } \\
(\mathrm{T} 2) \rightarrow \text { PE }(\mathrm{T} 3)\end{array}$ & & & & & .05 & {$[.01 ; .12]$} \\
\hline
\end{tabular}




\section{Discussion}

We extend the knowledge about university students' PE, which becomes critical to face the university-to-work transition in an increasingly volatile labour market. We draw on COR theory (Hobfoll et al., 2018) and the CSM model (Lent \& Brown, 2013) to shed light on how Universities can provide students with valuable career resources like PE. Our results confirm that support from teaching staff predicts students' PE over time, highlighting that, besides what is taught at university, teaching behaviour and methods (namely, how it is taught) are pivotal to make it meaningful and useful. Therefore, students see themselves prepared for the world of work and, in turn, the perceived likelihood to obtain suitable employment raises. This finding aligns with PE conceptualisation that sees it as also shaped by contextual factors (Vanchercke et al., 2014) and with the COR tenets that understand personal resources as a product of supportive organisational factors (Hobfoll et al., 2018). The mediation of selfefficacy remarks on the mechanisms through which supportive teaching raises students' PE. Moreover, it corroborates the critical role of self-efficacy to foster a sense of mastering over career-related endeavours (Lent \& Brown, 2013).

At a practical level, our results suggest shifting the pedagogical practice to a student-centred approach. Students can be supported in scaffolding the knowledge they acquire and preparing themselves to face the labour market's reality. University teachers should then be encouraged to update their teaching methods to devote their efforts to strengthen the usefulness and value of what they teach (Ödalen et al. 2020). The role of self-efficacy leads us to suggest that these teaching methods should include self-efficacy-enhancing behaviours. For instance, they can provide students with means to test their learning by work-based practice in the classroom, with examples from reliable models (i.e. alumni or professional experts) or formative feedback.

Further research is advocated to address some of this study's limitations. More attention to the fluctuations of the resources under investigation is needed. Moreover, additional work is required to refine the instrument used here to assess support from teaching staff. Lastly, future research should control for variables that affect how people estimate their PE. For instance, a replication of this study could account for the type of degree and home university of the participants to determine whether these variables affect the results obtained herein.

\section{References}

Álvarez-González, P., López-Miguens, M. J., \& Caballero, G. (2017). Perceived employability in university students: developing an integrated model. Career Development International, 22(3), 280-299. https://doi.org/10.1108/CDI-08-2016-0135 
Berntson, E., \& Marklund, S. (2007). The relationship between perceived employability and $\begin{array}{lllll}\text { subsequent health. Work \& 279-292. } & \text { Stress, }\end{array}$ https://doi.org/10.1080/02678370701659215

Dacre Pool, L., \& Sewell, P. (2007). The key to employability: developing a practical model of graduate employability. Education+ Training, 49(4), 277-289. https://doi.org/10.1108/00400910710754435

Donald, W. E., Ashleigh, M. J., \& Baruch, Y. (2018). Students' perceptions of education and employability: Facilitating career transition from higher education into the labor market. Career Development International, 23(5), 513-540. https://doi.org/10.1108/CDI-092017-0171

Donald, W. E., Baruch, Y., \& Ashleigh, M. (2019). The undergraduate self-perception of employability: Human capital, careers advice, and career ownership. Studies in Higher Education, 44(4), 599-614. https://doi.org/10.1080/03075079.2017.1387107

Elvira, Q., Beausaert, S., Segers, M., Imants, J., \& Dankbaar, B. (2016). Development and validation of a supportive learning environment for expertise development questionnaire (SLEED-Q). Learning Environments Research, 19(1), 17-41. https://doi.org/10.1007/s10984-015-9197-y

Fugate, M., Kinicki, A. J., \& Ashforth, B. E. (2004). Employability: A psycho-social construct, its dimensions, and applications. Journal of Vocational behavior, 65(1), 14-38. https://doi.org/10.1016/j.jvb.2003.10.005

González-Romá, V., Gamboa, J. P., \& Peiró, J. M. (2016). University graduates' employability, employment status, and job quality. Journal of Career Development, 45(2), 132-149. https://doi.org/10.1177/0894845316671607

Hayes A. F. (2018). Introduction to Mediation, Moderation, and Conditional Process Analysis: A Regression-Based Approach (2nd Ed.). New York, NY: The Guilford Press.

Hobfoll, S. E., Halbesleben, J., Neveu, J. P., \& Westman, M. (2018). Conservation of resources in the organisational context: The reality of resources and their consequences. Annual Review of Organizational Psychology and Organizational Behavior, 5, 103-128. https://doi.org/10.1146/annurev-orgpsych-032117-104640

Jackson, D., \& Tomlinson, M. (2020). Investigating the relationship between career planning, proactivity and employability perceptions among higher education students in uncertain labour market conditions. Higher education, 1-21. https://doi.org/10.1007/s10734-01900490-5

Lent, R. W., \& Brown, S. D. (2013). Social cognitive model of career self-management: Toward a unifying view of adaptive career behavior across the life span. Journal of Counseling Psychology, 60 (4), 557 - 568. https://doi.org/10.1037/a0033446

Liu, X., Peng, M. Y. P., Anser, M. K., Chong, W. L., \& Lin, B. (2020). Key Teacher Attitudes for Sustainable Development of Student Employability by Social Cognitive Career Theory: The Mediating Roles of Self-Efficacy and Problem-Based Learning. Frontiers in Psychology, 11. https://doi.org/10.3389/fpsyg.2020.01945

Monteiro, S., Almeida, L. and García-Aracil, A. (2020). "'It's a very different world": work transition and employability of higher education graduates". Higher Education, Skills and Work-Based Learning, Vol. ahead-of-print No. ahead-of-print. https://doi.org/10.1108/HESWBL-10-2019-0141 
Ödalen, J., Brommesson, D., Erlingsson, G. Ó., Schaffer, J. K., \& Fogelgren, M. (2019). Teaching university teachers to become better teachers: the effects of pedagogical training courses at six Swedish universities. Higher Education Research \& Development, 38(2), 339-353. https://doi.org/10.1080/07294360.2018.1512955

Römgens, I., Scoupe, R., \& Beausaert, S. (2020). Unraveling the concept of employability, bringing together research on employability in higher education and the workplace. Studies in Higher Education, 45(12), 2588-2603.

Rothwell, A., Jewell, S., \& Hardie, M. (2009). Self-perceived employability: Investigating the responses of post-graduate students. Journal of vocational behavior, 75(2), 152-161. https://doi.org/10.1016/j.jvb.2009.05.002

Vanhercke, D., De Cuyper, N., Peeters, E., \& De Witte, H. (2014). Defining perceived employability: a psychological approach. Personnel Review, 43(4), 592-605. https://doi.org/10.1108/PR-07-2012-0110

Yizhong, X., Lin, Z., Baranchenko, Y., Lau, C. K., Yukhanaev, A., \& Lu, H. (2017). Employability and job search behavior: A six-wave longitudinal study of Chinese university graduates. Employee Relations, 39(2), 223-239. https://doi.org/10.1108/ER02-2016-0042 